\title{
Update on the use of alitretinoin in treating chronic hand eczema
}

This article was published in the following Dove Press journal:

Clinical, Cosmetic and Investigational Dermatology

17 April 2010

Number of times this article has been viewed

\author{
Pedram Ghasri' \\ Noah Scheinfeld ${ }^{2}$ \\ 'University of California, Irvine \\ School of Medicine, Irvine, CA, \\ USA; ${ }^{2}$ Department of Dermatology, \\ Columbia University, School of \\ Medicine, New York, USA
}

\begin{abstract}
Chronic hand eczema is a debilitating dermatological condition with significant economic, social, and functional impacts. To date, conventional treatments such as topical corticosteroids, phototherapy, and systemic immunosuppressants have yielded disappointing results, owing to either a lack of efficacy or significant adverse events. Oral alitretinoin (9-cis-retinoic acid) is a unique panagonist retinoid with immunomodulatory and antiinflammatory activity that has emerged as a novel treatment for chronic hand eczema. Several large-scale clinical studies have demonstrated oral alitretinoin's high efficacy rate of $28 \%$ to $89 \%$, its safe tolerability profile, and its positive impact on quality of life, validating it as a therapeutic option for patients with severe chronic hand eczema refractory to standard treatment.
\end{abstract}

Keywords: hand eczema, alitretinoin, 9-cisretinoic acid

\section{Chronic hand eczema Background}

Eczema is the most common dermatological disorder of the hands, with an annual prevalence of up to $12 \%$ and $16 \%$ in parts of Europe and the United States, respectively. ${ }^{1,2}$ Hand eczema is characterized by vesicles, papules, erythema, edema, scaling, fissures, and hyperkeratosis, as well as pruritic and painful symptoms. ${ }^{3,4}$ While there is no specific morphological classification system, clinical subtypes include vesicular, atopic, endogenous, discoid, acral, irritant, pompholyx, and hyperkeratotic eczema. ${ }^{5}$ Included in the differential diagnosis are irritant contact dermatitis, allergic contact dermatitis, endogenous eczema, psoriasis/pustulosis, fungal infection, keratoderma, lichen planus, and granuloma annulare. ${ }^{6}$

Hand eczema has a multi-factorial etiology, involving both endogenous and exogenous factors. ${ }^{7}$ The primary endogenous predisposing factor is a history of atopy, which is the underlying etiology in as high as $50 \%$ of affected individuals. ${ }^{3}$ Genetic inheritance also plays a role, as demonstrated by a recent population-based twin cohort study. ${ }^{8}$ Exogenous factors primarily include exposure to irritants (ie, food, oils, soap, solvents), and contact allergens (ie, nickel, chromate, rubber). Occupational exposure to these causative agents, primarily among dressers, cooks, healthcare workers, for example, are the most common causes of hand eczema. ${ }^{9}$ The interrelatedness of these etiologies renders it difficult to isolate and remove the offending agents, and is therefore a factor for development of hand eczema into a chronic, relapsing course.

When hand eczema persists for more than 6 months despite therapeutic measures, it is considered to be a chronic form. ${ }^{6}$ This variant of hand eczema develops in

submit your manuscript $\mid$ www.dovepress.com 
$5 \%$ to $7 \%$ of affected individuals and has significant social, psychological, occupational, and economic impacts. ${ }^{10,11}$ Not only does this painful condition affect the utility of the hands in performing mechanical work, but the often disfiguring manifestations lead to negative social stigmata. ${ }^{3} \mathrm{~A}$ recent cross-sectional, multi-center study of 416 patients demonstrated that affected individuals had a significantly decreased quality of life, which was directly correlated to the severity of their disease. ${ }^{12}$

\section{Management}

A broad variety of both pharmacological and nonpharmacological strategies exist for the management of chronic hand eczema. These are usually delivered in a step-wise approach and begin by lifestyle modifications, including educating the patient about the avoidance of irritants and allergens, the avoidance of occupational-related irritation, and the use of emollients. ${ }^{6}$ A recent clinical study demonstrated that petroleum-based emollients and skin lipid-based emollients are equally effective therapeutic measurements for hand eczema, and patients should be encouraged to use them as an adjunct to other therapies. ${ }^{13}$ Topical steroids are usually the first-line pharmacological measure, but their use is limited by the adverse effects of skin atrophy, tachyphylaxis, potential adrenal suppression, and their futility in treating severe manifestations. ${ }^{14,15}$ Phototherapy with UVA-1 and UVB has been successfully used in the treatment of chronic hand eczema, but the inadequacy of evidence-based trials has limited its use. ${ }^{16,17}$ Systemic oral immunosuppressants, such as azathioprine, ciclosporin, and mycophenolate mofetil, have also been used with various responses. However, most of these are not licensed for the treatment of chronic hand eczema, owing to the lack of clinical evidence supporting their lack of efficacy and safety. Oral corticosteroids are also an option, but their long-term use is limited by well-studied adverse affects such as osteoporosis, hyperglycemia, cataracts, hypertension, and immunosuppression. ${ }^{18}$ A recent epidemiological study reviewing various clinical trials from 1977 to 2003 , which mostly involved the use of the above-mentioned topical steroids, systemic immunosuppressants, and UV irradiation, concluded that the poor quality of the studies was not sufficient to dictate clinical management of chronic hand eczema. ${ }^{19}$

The high prevalence of chronic hand eczema, its adverse impact on quality of life, and its failure to respond to standard therapeutic measures has ignited much recent interest in the search for an effective and tolerable medication.

\section{Alitretinoin}

\section{Background}

Oral alitretinoin (9-cis-retinoic acid; Toctino ${ }^{\circledR}$; Basilea Pharmaceuticals, Ltd., United Kingdom), an endogenous retinoid, is the only drug that has been specifically approved as a treatment option for adults with chronic hand eczema unresponsive to topical steroids. ${ }^{6}$ Retinoids are naturally occurring and synthetic derivatives of vitamin A, which plays an important role in the immune system by enhancing cytotoxicity, T-cell proliferation, and, under some conditions, B-cell proliferation. ${ }^{20}$ Concurrently, retinoids are also involved in fetal development, bone formation, cell proliferation, cell differentiation, apoptosis, hematopoiesis, and vision. ${ }^{21}$ These influences are mediated through the binding and subsequent activation of two types of intracellular receptors: retinoic acid receptors (RARs) and retinoid $X$ receptors (RXRs), which each contain three different subgroups, $\alpha, \beta$, and $\gamma \cdot{ }^{22,23}$ While other retinoids are limited in their binding to subgroups of either RARs or RXRs, alitretinoin is a unique panagonist that binds to all six retinoid receptors with high affinity, with a greater affinity for RARs than for RXRs. ${ }^{24}$

Given its effects on cell proliferation, alitretinoin is a potent teratogen and is therefore contraindicated in pregnant women and women who might become pregnant during the course of treatment. ${ }^{25}$ Moreover, studies on rat embryos have demonstrated that it can cause deleterious malformations at the second visceral arch. ${ }^{26}$ Alitretinoin's effects on cell proliferation have been exploited for beneficial effects as well; a recent study demonstrated its ability to induce apoptosis in breast cancer cells. ${ }^{27}$ In addition to exerting its effects on cell proliferation, alitretinoin has also been shown to produce an anti-inflammatory response by inhibiting the production of nitric oxide and such proinflammatory molecules as tumor necrosis factor (TNF)- $\alpha$, interleukin (IL)-1 $\beta$, and IL-12 p40. ${ }^{28}$ Since eczema is mediated through the Th1 cellular immune response, the inhibition of these cytokines by alitretinoin could explain its therapeutic efficacy. The immunological manipulation by oral alitretinoin was also the basis for two phase II trials in the treatment of AIDS-related Kaposi's sarcoma, a cutaneous tumor mediated by HHV-8. 60 and 57 participants received treatment for a median of 15 weeks, with an overall response rate of $37 \%$ and $39 \%$, respectively. Yet despite its efficacy, the investigators concluded that serious adverse events at high doses, such as pancreatitis and hypercalcinuria, limit its potential use for the treatment of Kaposi's sarcoma. ${ }^{29,30}$ 
The metabolic effects of alitretinoin have also been extensively studied. It was recently shown to increase sex steroid synthesis in the rat hippocampus and therefore play a role in reproductive behavior. ${ }^{31}$ It was also shown to have protective effects against ischemia-induced brain injury in rats, with implications for its use in patients susceptible to strokes. ${ }^{32}$

Oral alitretinoin has only been clinically approved for its use in chronic hand eczema, but recent studies have demonstrated its potential use in other dermatologic settings. In a small study with six patients who were treated for the hand eczema, alitretinoin was also shown to be effective in treating lesions of their extrapalmar atopic eczema. ${ }^{33}$ Furthermore, a recent case report of two patients treated with alitretinoin for palmoplantar hyperkeratotic-rhagadiform had a surprising clinical improvement of their Sezary syndrome and mycosis fungoides, implicating its potential use for cutaneous T-cell lymphomas. ${ }^{34}$

While alitretinoin potentially has profound dermatological and non-dermatological applications, this review focuses on its treatment for chronic hand eczema.

\section{Clinical studies (Table I)}

In a pilot open-label study in 1999, thirty-eight patients (19 men and 19 women) with chronic hand eczema unresponsive to conventional treatment were treated with 20-40 mg of oral alitretinoin for 1 to 5 months. ${ }^{25}$ The various classifications of their hand eczema included hyperkeratotic palmar eczema, fingertip eczema, pompholyx, and discoid eczema. Lesions and symptoms consisting of erythema, vesicles/papules, desquamation, hyperkeratosis, rhagades, and pruritis/pain, were objectively recorded by the physicians on a 4 point scale $(0=$ none, $1=$ slight, $2=$ moderate, $3=$ marked, $4=$ severe), and the reduction of their total score was expressed in a percentage. The patients assessed their own responses subjectively using the same 4 point scale. Side effects, such as headache, chelitis, conjunctivitis, and other mucocutaneous manifestations, were similarly recorded on a 4 point scale. Objective assessment by the physicians determined that $55 \%$ of the patients showed a "very good" response, 34\% showed a "good response," 2 patients showed a "moderate" response, and 2 patients did not show any response. The mean reduction of the total lesions and symptoms was $86 \%$ in the 36 patients who responded to treatment, with all various forms responding in a similar manner. Subjective assessment by the patients yielded similar results, as $66 \%$ believed they showed a "very good" response, 26\% believed they showed a "good" response, 1 felt a "moderate" response, and 2 did not believe they responded to the treatment. 7 patients experienced a recurrence of their lesions after discontinuation of the therapy, but a second regimen of treatment resulted in a successful response similar to the first course, thereby demonstrating a lack of resistance to the medication. Only mild side effects related to hypervitaminosis A were noted, namely transient headache, chelitis, transient flushing, and conjunctivitis. Overall, the pilot study demonstrated the efficacy of alitretinoin, as $89 \%$ of the patients assessed by the physician and $92 \%$ assessed by the patients showed a positive therapeutic response with minimal side effects.

Table I Summarized results of clinical trials of oral alitretinoin in the treatment of refractory chronic hand eczema

\begin{tabular}{|c|c|c|c|c|c|c|}
\hline Investigators & Date of study & Patients & Type of study & Alitretinoin doses & $\begin{array}{l}\text { Duration of } \\
\text { treatment }\end{array}$ & Responders \\
\hline Bollag and $\mathrm{Ott}^{24}$ & 1999 & 38 patients & $\begin{array}{l}\text { Exploratory } \\
\text { open-label }\end{array}$ & $\begin{array}{l}20 \mathrm{mg}, 40 \mathrm{mg} \text { once } \\
\text { daily }\end{array}$ & $\begin{array}{l}\text { I-5 months } \\
\text { (mean } \\
2.3 \text { months) }\end{array}$ & $\begin{array}{l}89 \% \text { assessed as "very } \\
\text { good" or "good" } \\
\text { response by physician }\end{array}$ \\
\hline Ruzicka et $\mathrm{al}^{34}$ & 2004 & 348 & $\begin{array}{l}\text { Randomized, } \\
\text { double-blind, } \\
\text { placebo-control, } \\
\text { prospective trial }\end{array}$ & $\begin{array}{l}\text { placebo, } 10 \mathrm{mg} \text {, } \\
20 \mathrm{mg}, 40 \mathrm{mg} \text { once } \\
\text { daily }\end{array}$ & 12 weeks & $\begin{array}{l}\text { PGA: } 39 \%, 41 \%, 53 \% \text {; } \\
\text { PaGA: 29\%, 34\%, 43\%; } \\
\text { TLSS: -59\%,-52\%, } \\
-70.5 \%(10 \mathrm{mg}, 20 \mathrm{mg}, \\
40 \mathrm{mg})\end{array}$ \\
\hline Ruzicka et $\mathrm{al}^{35}$ & 2008 & 1032 & $\begin{array}{l}\text { Randomized, } \\
\text { double-blind, } \\
\text { placebo-control, } \\
\text { prospective trial }\end{array}$ & $\begin{array}{l}\text { placebo, } 10 \mathrm{mg}, \\
30 \mathrm{mg} \text { once daily }\end{array}$ & I2-24 weeks & $\begin{array}{l}\text { PGA: } 28 \%, 48 \%, \text { PaGA: } \\
\text { 24\%, 40\%; mTLSS: -56\%, } \\
-75 \%,(10 \mathrm{mg}, 30 \mathrm{mg})\end{array}$ \\
\hline Bissonnette et $\mathrm{al}^{37}$ & 2009 & $\begin{array}{l}\text { I I } 7 \text { (patients } \\
\text { who relapsed } \\
\text { from } 2008 \text { trial) }\end{array}$ & $\begin{array}{l}\text { Randomized, } \\
\text { double-blind, } \\
\text { placebo-control, } \\
\text { prospective trial }\end{array}$ & $\begin{array}{l}\text { placebo, } 10 \text { mg, } \\
30 \text { mg once daily }\end{array}$ & I2-24 weeks & $\begin{array}{l}\text { PGA: } 48 \%, 80 \% \text {; PaGA: } \\
38 \%, 76 \% \text {; mTLSS: 7I\%, } \\
92 \% \text { (10 mg, } 30 \mathrm{mg})\end{array}$ \\
\hline
\end{tabular}

Abbreviations: PGA, physician's global assessment; PaGA, patient's global assessment;TLSS, total lesion symptom score. 
In a larger randomized, double-blind, placebo-control study in 2004, alitretinoin was again determined to be an efficacious and well-tolerated treatment for the treatment of refractory chronic hand eczema. ${ }^{35}$ The study was held in 43 clinics across Europe, enrolling 319 patients with moderate or severe refractory chronic hand eczema. Patients were randomized into four treatment groups of placebo, $10 \mathrm{mg}$, $20 \mathrm{mg}$, and $40 \mathrm{mg}$ of oral alitretinoin taken once a day for 12 weeks, and assessed at the end of the study as well as at a 3 month follow-up. The primary efficacy measure for the therapeutic response used by the researchers were the physician's global assessment (PGA) of overall severity, which was categorized into "clear," "almost clear," "mild," "moderate," and "severe." Patients were considered to be responders if they were rated as "clear" (no residual visible dermatitis) or "almost clear" (minimal erythema and/or scaling) at the end of the 12-week study. The total lesion symptom score (TLSS), the patient's global assessment (PaGA) of improvement, and the extent of disease were used as secondary efficacy measures. At the end of the study, the PGA assessment yielded results of $27 \%, 39 \%, 41 \%$, and $53 \%$ responders to placebo, $10 \mathrm{mg}, 20 \mathrm{mg}$, and $40 \mathrm{mg}$ doses, respectively. The researchers suggested that the response rate in the placebo group may be related to a variety of factors such as the natural course of the disease, placebo effects, or changes in influential factors of the disease (eg, climate, level of stress, occupation). The Cochran-Armitage trend test demonstrated a significant dose-dependent effect $(P<0.001)$. The PaGA assessment yielded similar results of $12 \%, 29 \%, 34 \%$, and $43 \%$ responders to the placebo, $10 \mathrm{mg}$, $20 \mathrm{mg}$, and $40 \mathrm{mg}$ doses, respectively, which was shown to be significant by $\chi^{2}$ test $(P=0.01$ for $10 \mathrm{mg}, P=0.002$ for $20 \mathrm{mg}$, and $P<0.001$ for $40 \mathrm{mg}$ ). For all dosages of alitretinoin, the median TLSS was higher compared to placebo (decreases of $25 \%, 59 \%, 52 \%$, and $70.5 \%$ for the placebo, $10 \mathrm{mg}, 20 \mathrm{mg}$, and $40 \mathrm{mg}$ doses, respectively). These results were shown to be significant $(P<0.001)$ with the Kruskal-Wallis test, and showed dose-dependence $(P<0.001)$ with the Jonckheere-Terpstra trend test). Safety evaluation of the drug at a 4 week follow-up revealed adverse effects only in the $40 \mathrm{mg}$ dosage group, which included headache, flushing, hyperlipidemia, decreased hemoglobin level, and decreased free thyroxin level. Three months after cessation of treatment, it was revealed that $26 \%$ of patients relapsed in a dose-independent manner. Overall, this study demonstrated that alitretinoin at well-tolerated doses effectively resulted in positive responses in up to $53 \%$ of patients and up to a $70 \%$ mean reduction in signs and symptoms.
In 2008, the results of a large, randomized, double-blind, placebo-controlled, parallel-group phase III study, the Benefit of Alitretinoin in Chronic Hand Dermatitis (BACH), were published. ${ }^{36}$ The study was conducted in 111 clinics throughout Europe and Canada, enrolling 1032 patients with severe refractory chronic hand eczema. The patients were randomized to three treatment groups of placebo $(n=205), 10 \mathrm{mg}(\mathrm{n}=418)$, or $30 \mathrm{mg}(\mathrm{n}=409)$ of oral alitretinoin administered once daily for up to 24 weeks. Patients stopped treatment if they responded within the first 12 weeks, while the others continued for the full duration of the study. The types of chronic hand eczema included hyperkeratotic, pompholyx, fingertip, and other, which was seen in $85 \%, 27 \%, 46 \%$, and $14 \%$ of patients, respectively. As with the previous study, the investigators used PGA as the primary efficacy parameter, whereby patients were considered to be responders if they were rated as "clear" or "almost clear." Secondary endpoints used were PaGA and a modified TLSS (mTLSS). The results of the investigation were concordant with the results in the previous study in 2004. The PGA results demonstrated a dose-dependent efficacy with $48 \%, 28 \%$, and $17 \%$ responders in the $30 \mathrm{mg}$, $10 \mathrm{mg}$, and placebo group, respectively. These results were confirmed by the secondary endpoints; the percentage of patients with clearing as determined by the PaGA were $40 \%, 24 \%$, and $15 \%$, and the median percentage reductions in $\mathrm{mTLSS}$ were $75 \%, 56 \%$, and $39 \%$ in the $30 \mathrm{mg}, 10 \mathrm{mg}$, and placebo groups respectively. There was not a uniform response rate amongst the various morphological classifications of hand eczema. For instance, in the $30 \mathrm{mg}$ treatment group, there was a $49 \%$ response rate in those with hyperkeratotic features and a 33\% response rate in those with the pompholyx variant. However, these classifications were not mutually exclusive so it would not be feasible to conclude that alitretinoin is more effective in one variant over the other. There was also a dose-dependence seen with the time to response, as it was significantly shorter in the $30 \mathrm{mg}$ group than the $10 \mathrm{mg}$ group $(P<0.001)$. The median time to relapse, which the investigators defined as a recurrence of $75 \%$ of the initial signs and symptoms in the absence of treatment, was 5.5 to 6.2 months. Adverse events were seen in $49.5 \%, 37.1 \%$, and $34.5 \%$ of the respective treatment groups, of which headache was the most commonly reported. Serious adverse events were minimal, with only $1 \%$ of patients in each treatment group reporting such a problem. One fatal event was reported in the $10 \mathrm{mg}$ group, although it was from a myocardial infarction unrelated to treatment. Typical retinoid-related 
laboratory abnormalities were noted, which included increases in serum cholesterol and triglyceride levels, and decreases in thyroid-stimulating hormone (TSH). As the largest clinical investigation on chronic hand eczema to date, this study demonstrated promising results of dosedependent efficacy of oral alitretinoin that were consistent with previous studies.

In 2009, the results of an extension of the BACH study were published. ${ }^{37}$ This investigation examined the efficacy and safety of oral alitretinoin in patients who initially responded well to treatment in the BACH study, but had relapsed within 24 weeks. 117 patients were randomized to three treatment groups; placebo $(\mathrm{n}=47), 10 \mathrm{mg}(\mathrm{n}=21)$, and $30 \mathrm{mg}(\mathrm{n}=49)$. Of the 31 previous responders to $10 \mathrm{mg}$ of alitretinoin, 10 received placebo and 21 received alitretinoin $10 \mathrm{mg} /$ day. Of the 73 previous responders to $30 \mathrm{mg}$ of alitretinoin, 24 received placebo and 49 received alitretinoin $30 \mathrm{mg} /$ day. The remaining participants in the study were 13 responders to previous treatment with placebo. Patients were treated for 24 weeks, but they stopped treatment if they responded within the first 12 weeks. Consistent with the previous large scale studies, the investigators used PGA as the primary efficacy parameter, and the PaGA and a mTLSS as the secondary parameters. Response rates were $80 \%(\mathrm{n}=39)$ in patients retreated with $30 \mathrm{mg}$ of alitretinoin, compared to $8 \%(n=2)$ for patients retreated with placebo. Response rates were $48 \%(\mathrm{n}=10)$ in patients retreated with $10 \mathrm{mg}$ of alitretinoin, compared to $10 \%(\mathrm{n}=1)$ for placebo. The secondary endpoints correlated with the PGA results; the median percentage reduction in MTLSS was $92 \%$ for the $30 \mathrm{mg}$ group and $71 \%$ for the $10 \mathrm{mg}$ group, while the PaGA results demonstrated that $76 \%(n=37)$ of patients in the $30 \mathrm{mg}$ group and $38 \%(\mathrm{n}=8)$ of patients in the $10 \mathrm{mg}$ group reported "clear" or "almost clear" hands. Adverse events were similar in frequency to the previous studies, with headache being the most common. Six patients in total ( 2 from each treatment group) withdrew from the study due to adverse events. Laboratory abnormalities were comparable to those reported in previous studies, namely hypercholesterolemia, increased triglyceride levels, and reduced TSH levels. This investigation was the first to show the long-term management of chronic hand eczema with intermittent systemic treatment, as it demonstrated the efficacy of retreatment with oral alitretinoin in patients who had previously relapsed.

Chronic hand eczema has a significant detrimental effect on quality of life, work productivity, activity impairment, and heath care costs. ${ }^{38}$ While previous investigations have demonstrated the clinical efficacy and tolerability of oral alitretinoin, there have been little to no data regarding its impact on the patient's quality of life. Blome et al recently presented a method whereby patients answered two sets of questionnaires to weigh the importance of their treatment needs (Patient Needs Questionnaire) against their achieved benefits (Patient Benefit Questionnaire). ${ }^{39}$ Patient's needs and achieved benefits included "to be pain free," "have lower personal treatment costs," and to "be able to touch others." The resultant Patient Benefit Index (PBI) was calculated from the importance of needs before therapy and the achievement of these needs. The instrument was utilized in an open label study in the safety and efficacy of oral alitretinoin in 249 patients with severe refractory hand eczema, in which the patients received 24 weeks of treatment with $30 \mathrm{mg}$ of oral alitretinoin daily. Based on the PBI, an overwhelming $84.3 \%$ of the patients had achieved at least minimal benefit from alitretinoin, and $14.1 \%$ of patients had their treatment needs completely fulfilled. The most common needs the patients wanted were to have their skin lesions improved, have confidence in therapy, get rid of itching, and to find a clear diagnosis and therapy. Likewise, the most common treatment benefits included having confidence in the therapy, having confidence in the therapy, and being free of itching, as well as to lead a normal daily life. Overall, all treatment needs after alitretinoin therapy had been achieved by at least $57 \%$ of the patients.

\section{Conclusion}

Chronic hand eczema is a debilitating disease with profound social, functional, psychological, and economical impacts. Standard management to date has failed to provide an efficacious and convenient form of therapy without dangerous adverse reactions. In view of several controlled clinical studies, oral alitretinoin has been proven to be an effective and safe treatment modality in refractory patients with a high disease burden. The current approved drug dosing is $30 \mathrm{mg}$ daily for 12 to 24 weeks, depending on the response, with a dose decrease to $10 \mathrm{mg}$ if any serious adverse reactions are experienced..$^{40}$ This is conceivably the most appropriate protocol, based on results of the clinical trials that demonstrated dose-dependent responses and minimal side effects. A recent appraisal by the National Institute for Health and Clinical Excellence (NICE) supported this protocol and made recommendations as to when treatment should be stopped. They advocated that the prescribing physician stop treatment once the patient has an adequate response, if the degree of hand eczema continued to be severe after 12 weeks of treatment, 
or if there was an inadequate response at 24 weeks. ${ }^{41}$ In the scenario where the patient relapses after having demonstrated an adequate response, re-administration of the drug would be a suitable option.

Oral alitretinoin has recently been approved in several European countries, but despite positive results, it still faces several challenges for US approval. This impedance can be attributed to revolving teratogenic concerns, its dose-dependent side effects, and a lack of long-term data on its effects on bone density. Furthermore, the pharmacoeconomics of the drug must be further explored prior to US approval. ${ }^{24}$ Lastly, adjunct therapies with alitretinoin must be further explored, as studies investigating these are lacking. Nonetheless, oral alitretinoin has emerged as a promising treatment for patients with chronic hand eczema refractory to conventional medications.

\section{Disclosures}

The authors declare no conflicts of interest.

\section{References}

1. Coenraads PJ, Nater JP, van der Lende R. Prevalence of eczema and other dermatoses of the hands and arms in the Netherlands. Association with age and occupation. Clin Exp Dermatol. 1983;8(5):495-503.

2. Fowler JF, Duh MS, Chang J, et al. A survey-based assessment of the prevalence and severity of chronic hand dermatitis in a managed care organization. Cutis. 2006;77(6):385-392.

3. Diepgen TL, Agner T, Aberer W, et al. Management of chronic hand eczema. Contact Dermatitis. 2007;57(4):203-210.

4. Holden C, Berth-Jones J, Burns T, Breathnach S, Cox N, Griffiths C. Rook's Textbook of Dermatology; 2004.

5. McFadden J. Hand eczema. Textbook of Contact Dermatitis. 3rd ed. Berlin: Springer; 2001:403-411.

6. English J, Aldridge R, Gawkrodger DJ, et al. Consensus statement on the management of chronic hand eczema. Clin Exp Dermatol. 2009;34(7):761-769.

7. Coenraads PJ. Hand eczema is common and multifactorial. J Invest Dermatol. 2007;127(7):1568-1570.

8. Lerbaek A, Kyvik KO, Ravn H, Menne T, Agner T. Incidence of hand eczema in a population-based twin cohort: genetic and environmental risk factors. Br J Dermatol. 2007;157(3):552-557.

9. Skoet R, Olsen J, Mathiesen B, Iversen L, Johansen JD, Agner T. A survey of occupational hand eczema in Denmark. Contact Dermatitis. 2004;51(4):159-166.

10. Cvetkovski RS, Rothman KJ, Olsen J, et al. Relation between diagnoses on severity, sick leave and loss of job among patients with occupational hand eczema. Br J Dermatol. 2005;152(1):93-98.

11. Cvetkovski RS, Zachariae R, Jensen H, Olsen J, Johansen JD, Agner T. Quality of life and depression in a population of occupational hand eczema patients. Contact Dermatitis. 2006;54(2):106-111.

12. Agner T, Andersen KE, Brandao FM, et al. Hand eczema severity and quality of life: a cross-sectional, multicentre study of hand eczema patients. Contact Dermatitis. 2008;59(1):43-47.

13. Kucharekova M, Van De Kerkhof PC, Van Der Valk PG. A randomized comparison of an emollient containing skin-related lipids with a petrolatum-based emollient as adjunct in the treatment of chronic hand dermatitis. Contact Dermatitis. 2003;48(6):293-299.

14. Tadicherla S, Ross K, Shenefelt PD, Fenske NA. Topical corticosteroids in dermatology. J Drugs Dermatol. 2009;8(12):1093-1105.
15. Feldman S. Tachyphylaxis to topical corticosteroids: the more you use them, the less they work? Clin Dermatol. 2006;24(3):229-230.

16. Sjovall P, Christensen OB. Local and systemic effect of UVB irradiation in patients with chronic hand eczema. Acta Derm Venereol. 1987;67(6):538-541.

17. Polderman MC, Govaert JC, le Cessie S, Pavel S. A double-blind placebo-controlled trial of UVA-1 in the treatment of dyshidrotic eczema. Clin Exp Dermatol. 2003;28(6):584-587.

18. Warshaw EM. Therapeutic options for chronic hand dermatitis. Dermatol Ther. 2004;17(3):240-250.

19. Van Coevorden AM, Coenraads PJ, Svensson A, et al. Overview of studies of treatments for hand eczema-the EDEN hand eczema survey. Br J Dermatol. 2004;151(2):446-451.

20. Moro JR, Iwata M, von Andriano UH. Vitamin effects on the immune system: vitamins A and D take centre stage. Nat Rev Immunol. Sep 2008;8(9):685-698.

21. Scheinfeld N, Michaels J, Serradell N, et al. Aletretinonin. Retinoid, treatment of chromic hand dermatitis. Drugs Future. 2007;32(11):943-951.

22. Germain P, Chambon P, Eichele G, et al. International Union of Pharmacology. LXIII. Retinoid X receptors. Pharmacol Rev. 2006;58(4): 760-772.

23. Germain P, Chambon P, Eichele G, et al. International Union of Pharmacology. LX. Retinoic acid receptors. Pharmacol Rev. 2006;58(4): 712-725.

24. Cheng C, Michaels J, Scheinfeld N. Alitretinoin: a comprehensive review. Expert Opin Investig Drugs. 2008;17(3):437-443.

25. Bollag W, Ott F. Successful treatment of chronic hand eczema with oral 9-cis-retinoic acid. Dermatology. 1999;199(4):308-312.

26. Ritchie HE, Brown-Woodman PD, Korabelnikoff A. Effect of co-administration of retinoids on rat embryo development in vitro. Birth Defects Res A Clin Mol Teratol. 2003;67(6):444-451.

27. Bonofiglio D, Cione E, Qi H, et al. Combined low doses of PPAR gamma and RXR ligands trigger an intrinsic apoptotic pathway in human breast cancer cells. Am J Pathol. 2009;175(3):1270-1280.

28. Xu J, Drew PD. 9-Cis-retinoic acid suppresses inflammatory responses of microglia and astrocytes. J Neuroimmunol. 2006;171(1-2):135-144.

29. Miles SA, Dezube BJ, Lee JY, et al. Antitumor activity of oral 9-cis-retinoic acid in HIV-associated Kaposi's sarcoma. AIDS. 2002; 16(3):421-429.

30. Aboulafia DM, Norris D, Henry D, et al. 9-cis-retinoic acid capsules in the treatment of AIDS-related Kaposi sarcoma: results of a phase 2 multicenter clinical trial. Arch Dermatol. 2003;139(2):178-186.

31. Munetsuna E, Hojo Y, Hattori M, et al. Retinoic acid stimulates 17 betaestradiol and testosterone synthesis in rat hippocampal slice cultures. Endocrinology. 2009;150(9):4260-4269.

32. Shen H, Luo Y, Kuo CC, et al. 9-Cis-retinoic acid reduces ischemic brain injury in rodents via bone morphogenetic protein. J Neurosci Res. 2009;87(2):545-555.

33. Grahovac M, Molin S, Prinz JC, Ruzicka T, Wollenberg A. Treatment of atopic eczema with oral alitretinoin. Br J Dermatol. 2009 Nov 3. [Epub ahead of print].

34. Molin S, Ruzicka T. Possible benefit of oral alitretinoin in T-lymphoproliferative diseases: a report of two patients with palmoplantar hyperkeratotic-rhagadiform skin changes and mycosis fungoides or Sezary syndrome. Br J Dermatol. 2009;161(6):1420-1422.

35. Ruzicka T, Larsen FG, Galewicz D, et al. Oral alitretinoin (9-cis-retinoic acid) therapy for chronic hand dermatitis in patients refractory to standard therapy: results of a randomized, double-blind, placebo-controlled, multicenter trial. Arch Dermatol. 2004;140(12):1453-1459.

36. Ruzicka T, Lynde CW, Jemec GB, et al. Efficacy and safety of oral alitretinoin (9-cis retinoic acid) in patients with severe chronic hand eczema refractory to topical corticosteroids: results of a randomized, double-blind, placebo-controlled, multicentre trial. $\mathrm{Br} J$ Dermatol. 2008;158(4):808-817.

37. Bissonnette R, Worm M, Gerlach B, et al. Successful retreatment with alitretinoin in patients with relapsed chronic hand eczema. $\mathrm{Br} J$ Dermatol. 2009 Nov 10. [Epub ahead of print]. 
38. Fowler JF, Ghosh A, Sung J, et al. Impact of chronic hand dermatitis on quality of life, work productivity, activity impairment, and medical costs. J Am Acad Dermatol. 2006;54(3):448-457.

39. Blome C, Maares J, Diepgen T, Jeffrustenbach S, Augustin M. Measurement of patient-relevant benefits in the treatment of chronic hand eczema - a novel approach. Contact Dermatitis. 2009;61(1): $39-45$.
40. English J. Alitretinoin (Toctino): new oral retinoid for chronic hand eczema. Prescriber. 2009:20(1):29-32.

41. Rodgers M, Griffin S, Paulden M, et al. Alitretinoin for severe chronic hand eczema: A NICE single technology appraisal. Pharmacoeconomics. 2010 Feb 4. [Epub ahead of print].

\section{Publish your work in this journal}

Clinical, Cosmetic and Investigational Dermatology is an international, peer-reviewed, open access, online journal that focuses on the latest clinical and experimental research in all aspects of skin disease and cosmetic interventions. All areas of dermatology will be covered; contributions will be welcomed from all clinicians and basic science researchers globally. This journal is indexed on CAS. The manuscript management system is completely online and includes a very quick and fair peer-review system, which is all easy to use. Visit http://www.dovepress.com/testimonials.php to read real quotes from published authors.

Submit your manuscript here: http://www.dovepress.com/clinical-cosmetic-and-investigational-dermatology-journal 